BLS 34, No 1 2008. DOI: http://dx.doi.org/10.3765/bls.v34i1.3589

(published by the Berkeley Linguistics Society and the Linguistic Society of America)

\title{
Presentation: From Comment to Topic
}

\author{
STEFAN HUBER \\ University of South Florida, Tampa
}

\section{Introduction}

Traditional descriptions of information structure (IS) have been focusing on intrasentential dichotomies such as topic-comment, background-focus, theme-rheme, and possibly presupposition-contrast (cf. Molnár 1993, Lambrecht 1994, Frey 2004 and many others). The goal of this paper is to argue for a new IS category presentation and to show its relevance and independence from other layers of IS. Presentation is regarded as an inherently pragmatic concept that can be expressed in a variety of marked syntactic constructions.

Consider, e.g., the following there is-construction, often labeled the presentational construction in English:

There is a man at the door. [He is selling shoelaces.]

Intuitively, the DP the man is properly introduced in this context since it is originally mentioned and then resumed and predicated upon. Such a basic strategy containing indefinites I will contrast below with more intricate structures, using examples from both German and English.

The organization of the paper is as follows: in section 1, I briefly discuss the theoretical syntactic and pragmatic assumptions regarding IS. In section 2 , the basic idea concerning presentation is outlined. It is shown that presentation has to be viewed as a two-step strategy, which parallels other IS dichotomies. Section 3 deals with marked presentational constructions in English and German, e.g., English "indefinite demonstratives" and German so-called "V2 relative clauses." In the final section 4 , I return to the theoretical framework and argue that the presentational steps do not coincide with other informational categories, such as rheme or topic, but that they must form an independent layer.

\section{Information Structure: Syntax and Pragmatics}

Some of the basic IS notions, such as topic, focus, and even contrast, have lately attracted a lot of attention within syntactic research, as they purportedly are responsible for numerous ordering phenomena at the surface. This not only 


\section{Stefan Huber}

applies to so-called discourse-configurational languages such as Hungarian, Finnish, and Basque (cf. Brody 1995, Järventaustta \& Molnár 2002, Arregi 2001), but presumably also to Romance (Rizzi 1997) and Germanic (Meinunger 1998, Frey 2004, den Dikken 2005). More specifically, IS categories are claimed to project syntactic phrases in the so-called C-domain, into which marked items have to be moved overtly in order to be interpreted appropriately. The obvious problem, at least for Germanic, is that IS categories such as focus or contrast also can be interpreted in situ, rendering informationally motivated movement (partially) optional.

The problem might be traced back to the assumption that IS is an inherently pragmatic, i.e. discourse-ordering, concept that interacts with syntax in a more or less principled way. Some such view is advocated by e.g. Molnár (1993) and I will adhere to this idea here. In Molnár's theory, IS is to be treated as a layered system of dichotomies that correspond to certain aspects of a discourse situation, as roughly sketched in (2):

Table 1. The layers of IS according to Molnár (1993)

\begin{tabular}{|l|lll|}
\hline Message & Topic $(\mathrm{T})$ & - & Comment $(\mathrm{C})$ \\
\hline Hearer & Theme $(\mathrm{Th})$ & - & Rheme $(\mathrm{Rh})$ \\
\hline Speaker & Background $(\mathrm{B})$ & - & Focus $(\mathrm{F})$ \\
\hline
\end{tabular}

The message layer can be divided into a part that the utterance is about (topic; $T)^{1}$ and a part that contains the actual IS predication (comment; $C$ ). Furthermore, the speaker organizes the utterance with regard to their assumptions as to hearer-old information (theme; Th) or hearer-new information (rheme; Rh). Finally, the speaker may mark the more important (focus; $F$ ) and less important (background; $B$ ) information.

In the prototypical case the categories $\mathrm{T} / \mathrm{Th} / \mathrm{B}$ and $\mathrm{C} / \mathrm{Rh} / \mathrm{F}$ overlap, as in (3):

$$
\text { (I met an old friend.) }[\mathrm{He}]_{\mathrm{T} / \mathrm{Th} / \mathrm{B}}[\text { used to be a professor }]_{\mathrm{C} / \mathrm{Rh} / \mathrm{F}} \text {. }
$$

Molnár stresses, though, that the layers are independent from each other, which leads to a wide array of distinctive IS patterns. In particular she points out that the categories topic and focus are not mutually exclusive, as has often been claimed, but that they rather apply on different levels. This can be demonstrated with sentences containing multiple foci (4a) or all-focused sentences that nevertheless display a topic-comment division (4b):

(4) a. (Who did what?) $[\text { Peter }]_{\mathrm{F} 1=\mathrm{T} 1}[\text { danced }]_{\mathrm{F} 2=\mathrm{C} 1}$ and $[\text { Mary }]_{\mathrm{F} 3=\mathrm{T} 2}[\text { sang }]_{\mathrm{F} 4=\mathrm{C} 2}$.

b. (What happened?) $\left[[\mathrm{A} \text { man }]_{\mathrm{T}}[\text { entered the store }]_{\mathrm{C}}\right]_{\mathrm{F}}$.

\footnotetext{
${ }^{1}$ This notion goes back to Reinhart's (1982) formulation of "aboutness.” Molnár also discusses other shades of topicaliy, for instance Chafe's (1976) "frame topics."
} 


\section{Presentation: From Comment to Topic}

Although a three-layer model can account for many IS types, it will become evident from the argumentation below that we have to assume yet another layer, namely presentation.

\section{The Basic Idea: Presentation as a Two-Step Strategy}

Re-regard example (1). The entity a man was argued to be properly introduced, i.e. presented, in the ongoing context. It is explicitly verbalized in a first sentence and then mentioned again and predicated upon in the ensuing sentence. I take these two steps to be fundamental to every presentation and will call them import $(I)$ and process $(P)$. Note that both steps are indispensible, i.e. the bare mentioning of an (indefinite) DP does not automatically trigger its presentation, cf. the contrast in (5):

(5) a. There is [a man $]_{\mathrm{I}}$ at the door. [He is selling shoelaces. $]_{\mathrm{P}}$

b. There is a man at the door. But I won't open it.

Only in (5a), a man is processed in the following sentence and is therefore properly presented. No such operation is carried out in $(5 b)$, as there is no corresponding process part. Hence, the presentation of a man does not take place.

Presentations in the sense above are not necessarily confined to sentence pairs, but can easily be extended to longer textual passages, where several sentences are used to process the newly introduced item in one cohesive chunk (6a). Moreover, presentations may occur recursively, meaning that another item can be imported within the process part of a previously presented entity, as in (6b):

(6) a. There is [a man $]_{\mathrm{I}}$ at the door.

[He is selling shoelaces. $]_{\mathrm{Pa}}$

$[\mathrm{He} \text { has a little suitcase and is wearing a funny suit. }]_{\mathrm{Pb}}$

$[\text { He doesn't strike me as a very serious person. }]_{\mathrm{Pc}}$

b. There is [a man $]_{11}$ at the door.

$[\text { He is selling [shoelaces }]_{12}$. $]_{\mathrm{P} 1}$

[They come in the colors black, brown and mauve. $]_{\mathrm{P} 2}$

It is also noteworthy that presentations do not seem to be restricted to indefinites. If the speaker is aware that a definite expression could be non-salient in the hearer's mind, they might want to re-import the expression before elaborating on it (see also section 3.2. below). This kind of strategy can be observed in (7):

I met [Peter Giles $]_{\mathrm{I}}$ again. [He is bald nowadays. $]_{\mathrm{P}}$

(7) shows that the speaker's intention is to direct the hearer's attention to a specific entity. Thus an import could be defined as a contextual insertion which the speaker holds to be a necessary preparation for the successful understanding 


\section{Stefan Huber}

of a following utterance. In this sense, a presentation is a hearer-oriented textorganizational strategy performed by the speaker.

The rather strong hypothesis that I will put forward here is that presentation is a pragmatic universal that is reflected in a wide variety of marked syntactic construction types. In the following, I will address some such constructions in both English and German.

\section{Presentational Constructions}

As indicated by example (7), presentational constructions are not confined to indefinite DPs. Limiting the discussion to nominal elements, I want to demonstrate how both indefinites and definites can occur as presentees.

\subsection{Indefinites}

\subsubsection{Simple Indefinites}

The simplest case to introduce an item into the ongoing context is to encode it as an indefinite, as in (1). In semantic terms, such an indefinite cannot receive a purely existential reading, but must be specific. Following von Heusinger (2002), I assume that a specific indefinite is "referentially anchored" to a discourse participant, in this case the speaker. Therefore, it stays "online" and is subject to further linguistic (i.e. discourse) operations. If it goes "offline" the intrinsic index variable of the DP is existentially bound. In other words, a pragmatic reflex of the specificity of an indefinite DP is that the speaker provides more information about its referent in the following context. This is exactly what happens in what was called the process part of a presentation above.

Note, though, that the reverse is not true, i.e. not every specific item is necessarily presented in a discourse. Regard the minimal difference in (8):

(8) a. Speaker A: Somebody forgot his valium this morning.

Speaker B: No doubt.

b. Speaker A: Look at that: Somebody forgot their valium this morning. Speaker B: Just grab it and be happy.

The discourse (8a) could occur in a scenario where two speakers observe a person performing spastic movements on the dance floor. Since the person is in plain sight, the gender (and number) can be determined, hence the possessive his. (8b), on the other hand, might be uttered when two speakers find a couple of valium pills on a table. Unable to determine who has forgotten them, speaker A resorts to the non-specific possessive their. Now note that his in (8a) refers to an individual that is co-textually given, which makes the DP somebody highly specific. However, this DP is not properly processed in the context and hence a presentation of somebody in the sense above does not take place.

So far, it seems as if presentations always involve two independent sentences. The examples in (9), however, display complex sentences containing a coordination (9a) and an appositive relative clause (9b; see also below, 3.2.3.). These 


\section{Presentation: From Comment to Topic}

constructions can be used for presentational purposes. On a closer look, they only seemingly contradict the "bi-sententiality" requirement:

(9) a. I met [some people $]_{I}$ in London and [they showed me the city $]_{P}$.

b. I met [some people $]_{\mathrm{I}}$ in London, [who showed me the city $]_{\mathrm{P}}$.

Although coordinations and appositive relative clauses allow for multiple proposition-embedding within the same clause, they often display background-focus structures of their own (Brandt 1990). At least on a pragmatic level, the two propositions contained in such configurations ought to be taken as independent structures. As for presentational sequences, it seems as if we have to assume separate focus domains for the parts in which the import and the process take place. I will return to this question in section 4 .

\subsection{2. "V2-Relative Clauses" in German (V2-RCs)}

An OV-language, German displays the finite verb in the last position of embedded clauses, including relative clauses (RCs). However, there seems to be a class of exceptional RCs showing the main clause order V2 (cf. Gärtner 2001, Endriss and Gärtner 2005). Some examples are given in (10):
a. Es war einmal ein König, der hatte eine schöne Tochter. there was once a king he had a beautiful daughter 'Once upon a time there was a king who had a beautiful daughter.'

b. Ich habe ein Land besucht, da kostet das Bier ein Vermögen. I have a country visited there costs the beer a fortune. 'I visited a country where beer costs a fortune.'

Gärtner (2001) points out numerous morphosyntactic differences between these constructions and regular (restrictive) relative clauses: The initial pronoun is rather demonstrative than relative (11), the "RCs" are always extraposed (12), and "RC"-internal material is immune to C-binding (13):

(11) a. Ich habe ein Land besucht, $*$ da/ $/{ }^{\mathrm{OK}}$ wo das Bier ein Vermögen kostet.

b. Ich habe ein Land besucht, ${ }^{\mathrm{OK}} \mathrm{da} /{ }^{*}$ wo kostet das Bier ein Vermögen.

(12) a. Ich habe ein Land \{wo das Bier ein Vermögen kostet\} besucht \{wo das Bier ein Vermögen kostet\}.

b. Ich habe ein Land $\{*$ da kostet das Bier ein Vermögen $\}$, besucht \{da kostet das Bier ein Vermögen\}.
a. ?? In Köln
traf $\mathrm{er}_{\mathrm{i}}$ Leute, die
haben.
in Cologne met he people they Hans not recognized have
b. In Köln traf er $\mathrm{i}_{\mathrm{i}}$ Leute, die haben Hans $\mathrm{i}_{\mathrm{i}}$ nicht erkannt.
'In Cologne Hans met people that didn't recognize him.' 


\section{Stefan Huber}

On the other hand, Gärtner argues that V2-RCs trigger the same reading as restrictive relative clauses. ${ }^{2}$ Therefore, he suggests the following hybrid syntactic analysis, which must be interpreted as some sort of "relative coordination." The most prominent feature is the empty coordinative head $\pi$ :

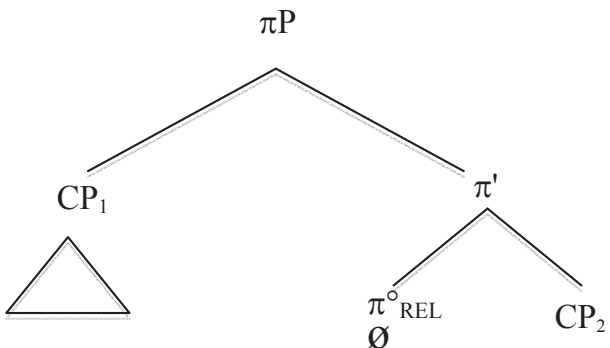

Ich habe el Land besucht

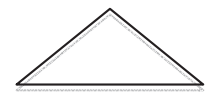

Das kostet das Bier Vermögen

The stipulation of a silent "relative coordinator" might appear somewhat dubious. Probably a regular (asyndetic) coordination might just do as well. I will assume that it is a demonstrative, rather than a relative connection between the two clauses that licenses such an unmediated coordination.

In any event, it seems as if the indefinite DP in the main clause meets exactly the necessary preconditions to function as a presentee: it is highly specific (i.e. it stays "online") and the speaker provides more restrictive information about it in the ensuing "RC," i.e. it is processed. The somewhat marked coordinative construction, on the other hand, can be regarded as a reflex of the tight correlation between the import and the process part. Hence I suggest the following IS for V2RCs:

Ich habe [ein Land $]_{\mathrm{I}}$ besucht, [da kostet das Bier ein Vermögen $]_{\mathrm{P}}$.

${ }^{2}$ In particular, Gärtner argues that V2-RCs do not trigger certain implicatures, just like restrictive relative clauses, but unlike regular coordinations:
(i)
Das Blatt hat eine Seite, die
the sheet has a/one page it is
ist
ganz completely
schwarz.
b. Das Blatt hat eine Seite, die ganz schwarz ist.
(ii) (\#) Das Blatt hat eine Seite und die ist ganz schwarz.

According to Gärtner, one can conclude only from (ii) that the sheet has only one page, which strides against our world knowledge. Gärtner takes this as an argument against a regular coordination. However, I do not necessarily regard (ii) as infelicitous: if one interprets eine Seite as specific such an implicature can be avoided ('the sheet has a certain page and it is black'). 


\section{Presentation: From Comment to Topic}

\subsection{3. "Syntactic Amalgams" in English}

Lambrecht (1988) discusses relative clauses in English that apparently violate the restriction on $\mathrm{RC}$-internal subject marking. Calling these constructions "syntactic amalgams," he points out their presentational character. Examples are given in (16):
a. There was a farmer
[RC had a dog]. ${ }^{3}$
b. I have a friend in the Bay Area [RC is a painter].

Although the RCs are subjectless, they are acceptable in these contexts. As with the German constructions above, the heads in these "amalgams" in English are specific and are processed in the following relative clause. Hence a proper presentation is carried out and I assume a similar IS for these constructions:

There was $[\mathrm{a} \text { farmer }]_{\mathrm{I}}[\mathrm{had} \text { a dog }]_{\mathrm{P}}$.

The licensing of the empty subject position within the relative clause might be an effect of the very presentational character of the construction: apparently there must never be any material between the import and the process clause, but these components must be adjacent. This "closeness" requirement might even lead to the phonological deletion of otherwise grammatically required function words. Note that the insertion of other material between the import and process clauses deteriorates the sentence:

?? There was a farmer here during the Great Depression had a dog.

\subsection{Definites}

\subsubsection{Simple Definites}

As pointed out above, the speaker can re-present an item that they want to activate in the hearer's mind, although it might technically be thematic knowledge. In this case, a definite DP can be re-imported before processing it, as shown in (7). Further examples for such a strategy are provided in (19):

a. I met [the Indian grocer $]_{\mathrm{I}}$ again. $\quad[\text { He seemed much older. }]_{\mathrm{P}}$

b. I often think of [my foster daughter $]_{\text {I. }}$ [She must be 22 years old now. $]_{\mathrm{P}}$

Note also that in German, proper names may marginally occur in constructions displaying "V2-RCs:"

\footnotetext{
${ }^{3}$ Lambrecht (1988) indeed presents an amalgam structure for these clauses, in which the head of the $\mathrm{RC}$ is represented simultaneously in the $\mathrm{RC}$ and the main clause. A discussion of his syntactic approach is beyond the scope of this article.
} 


\section{Stefan Huber}

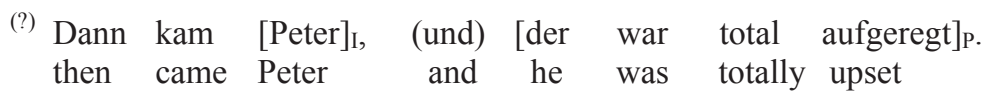
'Peter came. He was very upset.'

Assuming that these constructions are always presentational, Peter must be the import. Hence definite imports should be licit.

\subsection{2. "Indefinite Demonstratives"}

Gundel et al. (1993) describe constructions in English, in which demonstrative determiners fail to render a definite reading of the underlying DP, as in (21):

I saw [this woman] $]_{\text {. }}$ [She just took my breath away.]P

Nevertheless, these "indefinite demonstratives" are highly specific, and refuse to go "offline." The following examples demonstrate this behavior:

(What happened to you yesterday?)
a. I saw this woman. ${ }^{\#} \varnothing$
b. I saw this woman. " Then I went shopping.
c. I saw this woman. ${ }^{\text {OK }}$ She just took my breath away.

An indefinite demonstrative needs to be resumed in the following context. If stranded (22a) or abandoned (22b) it is interpreted as a regular (definite) demonstrative. The only proper way of using indefinite demonstratives is to resume and predicate on them, which is exactly what was described as a presentational strategy above (hence the indexes in example 21). Therefore, I regard indefinite demonstratives as an unambiguous presentational strategy.

\subsubsection{Appositive Relative Clauses (AppRCs)}

Appositive relative clauses provide further illustration of the phenomenon of presentation. Remember that these RCs show a certain informational and phonological independence, i.e. they display a background-focus structure of their own. In (23) the two separate nuclear accents have been marked with capital letters: ${ }^{4}$

I met $[\mathrm{MAX}]_{\mathrm{I}}$ again, [who had gotten MARried $]_{\mathrm{P}}$.

The separate focus domains in examples such as (23) are reminiscent of the examples with simple definites (19). Since every independent sentence must display at least one nuclear focus, the difference between (19) and (23) boils

\footnotetext{
${ }^{4}$ Lambrecht (1988) argues that there is a difference between (mid) AppRCs and (final) "continuative" relative clauses, the latter modifying the entire preceding clause. In this respect (23) could be ambiguous. However, I am not sure whether there is a clear semantic and IS distinction between those two RC types. I will have to leave this question to further research.
} 


\section{Presentation: From Comment to Topic}

down to the fact that the two foci in (23) have been realized within the same sentence. Other than that (and the realization of the resumed item as a relative pronoun), (23) seems to express the same presentational strategy, i.e. a specific DP is imported and processed, as indicated by the indexes. Therefore, I assume that (at least some) AppRCs can be used for presentational purposes.

\section{Back to Theory: The Relevance of Import and Process}

The discussion so far has shown that presentations can be realized in numerous (marked) ways. The question to be addressed now is whether we can argue for the necessity of the categories import and process theoretically. In other words, do we really need those new categories or can they be derived from the already existing ones such as rheme, topic, focus, etc.? In the following I want to show that there is reason to assume that import and process are not identical with other informational concepts and that the presentational layer must be independent.

\subsection{Import-Process vs. Other Dichotomies}

Intuitively, an imported item should be somewhat new. Otherwise the speaker would not make the effort of presenting it. Nevertheless, definite DPs are acceptable as presentees, as shown in the examples (7) and (19) above.

Now consider a prototypical theme-rheme structure in which a presentation occurs:

\section{$[\mathrm{I}]_{\mathrm{Th} 1}\left[\mathrm{saw}[\mathrm{a} \text { bird }]_{\mathrm{I}}\right]_{\mathrm{Rh} 1} \cdot\left[[\mathrm{It}]_{\mathrm{Th} 2}[\text { had no feathers }]_{\mathrm{Rh} 2} \cdot\right]_{\mathrm{P}}$}

Both in the import and the process clauses, thematic and rhematic material can occur. As is pointed out by the indexes, these informational domains do not coincide with the categories import and process. Hence we have to assume that import and process must apply on a level different from the theme-rheme structure.

To capture the "newness" of the imported item, various means could be suggested (see, e.g., the cognitive scales suggested by Gundel et al. 1993). For our purposes a secondary feature within the category $[ \pm$ thematic $]$ information might suffice. Let us call this feature [ \pm activated]. Thus thematic (and possibly rhematic) information can be assumed to be salient ([+ activated]) or not ([- activated]). Regarding imports we can then conclude that they always have to be [- activated], either because they are completely new (= rhematic) or given, but non-salient (= thematic, but [- activated]).

Another intuitive component of imports is that they seem to trigger an "aboutness" reading. Endriss and Gärtner (2005) go as far as to call the "heads" of V2-RCs (described as imports above) "pre-topics." Obviously, the speaker introduces the item to be presented in order to say something about it, i.e. the item stays "online." Nevertheless, a more fine-grained IS of a presentational sequence shows that topic and import are not the same thing: 


\section{Stefan Huber}

(Speaking of Paul, let me tell you this:)

$\left.[\text { Paul }]_{\mathrm{T} 1}[\text { met [this woman }]_{\mathrm{I}}\right]_{\mathrm{C} 1}$. [[She $\left.]_{\mathrm{T} 2}[\text { totally bewitched him }]_{\mathrm{C} 2} \cdot\right]_{\mathrm{P}}$ (They even got married!)

The first sentence shows that the import, i.e. the indefinite demonstrative $a$ woman, is distinct from the sentential (aboutness) topic Paul. Moreover, in the process clause a second topic-comment structure can be discerned. Thus the topiccomment structure and the presentational layer occur on different levels.

Finally, it can also be shown that the presentational layer must be kept apart from the background-focus structure. For instance, the background-focus structure of (25) is largely identical with its topic-comment structure, as demonstrated in (26). Again, the import-process structure and the background-focus structure do not overlap, which underlines the necessity of separating the presentational layer from all other IS dichotomies, including the background-focus structure:

$$
[\text { Paul }]_{\mathrm{B} 1}\left[\text { met }[\text { this woman }]_{\mathrm{I}}\right]_{\mathrm{F} 1} \text {. }\left[[\text { She }]_{\mathrm{B} 2}[\text { totally bewitched him }]_{\mathrm{F} 2} .\right]_{\mathrm{P}}
$$

\subsection{The Domains of Import and Process}

Let us return to a question that was raised in section 3.1.1.: Do the import part and the process part obligatorily have to be realized in separated sentences? Using example (9), it was indicated above that the two domains do not have to be syntactically independent, which was further illustrated with V2-RCs in German and "syntactic amalgams" in English. Therefore it seemed as if not so much a syntactic, but rather a pragmatic independence (separate background-focus structures) was the necessary condition for a successful presentation.

A problem for this focus-based approach comes from V2-RCs in German. As Gärtner (2001) and Endriss and Gärtner (2005) note, V2-RCs can be realized with one single focus domain, which comprises both the "main" and the "relative" clause. If V2-RCs constructions always present the "head" of the "RC," one faces the dilemma that there is no necessary double background-focus structure:

$$
\text { [Ich habe [ein Land } \left.\left.]_{\mathrm{I}} \text { besucht, [da kostet das Bier ein Vermögen }\right]_{\mathrm{P} .}\right]_{\mathrm{F}}
$$

Fortunately, the problem can be solved by turning to the very definition of a process. According to the characterization above, in the process clause of a presentational sequence a newly imported item is resumed and predicated upon. This is nothing else than to say that a process by definition must display a topiccomment structure. So the more adequate description is that it is two comment domains rather than two focus domains that are required for a successful presentation. In such a configuration the presentee is promoted from being an import in a first comment domain to becoming the topic in a second topic-comment structure. The strategy can be carried out by either producing two separate syntactic units, as in the case of simple (in-) definite or indefinite demonstratives (28a), or just one, which might either be divided into two focus domains, as in the case of 


\section{Presentation: From Comment to Topic}

appositive RCs (28b), or left undivided, as in the case of V2-RCs constructions $(28 \mathrm{c}):^{5}$

(28) a. $[\mathrm{Paul}]_{\mathrm{T} 1}\left[\text { met }[\text { this woman }]_{\mathrm{I}}\right]_{\underline{\mathrm{C1}}}$.

$\left.\left[[\mathrm{She}]_{\mathrm{T} 2} \text { [totally bewitched him }\right]_{\underline{\mathrm{C}} 2} \cdot\right]_{\mathrm{P}}$

b. $[\mathrm{I}]_{\mathrm{B} 1=\mathrm{T} 1}\left[\text { met }[\mathrm{MAX}]_{\mathrm{I}} \text { again }\right]_{\mathrm{F} 1=\mathrm{C} 1}$, $\left[[\text { who }]_{\mathrm{B} 2=\mathrm{F} 2}[\text { had gotten MARried }]_{\mathrm{F} 2=\mathrm{C} 2}\right]_{\mathrm{P}}$.

c. $\left[[\mathrm{ICh}]_{\mathrm{T} 1}\left[\text { habe }[\text { ein Land }]_{\mathrm{I}} \text { besucht }\right]_{\underline{\mathrm{C}}}\right.$, $\left.\left[[\mathrm{da}]_{\mathrm{T} 2}[\text { kostet das Bier ein Vermögen }]_{\mathrm{C} 2}\right]_{\mathrm{P}}\right]_{\mathrm{F}}$

\section{Summary}

It then seems as if there is sufficient evidence to assume a separate presentational layer. Extending Molnár's (1993) model, one might ask whether this layer pertains to one of the existing dimensions of communication (message, speaker, hearer), or whether it should form an independent layer. Although I will have to leave an in-depth discussion of this question open here, I will describe the presentational layer as a separate dichotomy. Since presentation obviously can have inter-sentential effects, the layer is named "context". Thus, an extension of Molnár's theory could be sketched as in table 2:

Table 2. Four layers of IS

\begin{tabular}{|l|ll|l|}
\hline & Sentence 1 & Sentence 2+ \\
\hline (Sentential) Message & Topic - Comment & \\
\hline Hearer & Theme - Rheme & \\
\hline Speaker & Background - Focus & \\
\hline Context & Import - Process $\}$ & $\{$ Process $\}$ \\
\hline
\end{tabular}

Further research will hopefully show whether even more layers of IS are necessary. Also, it might worthwhile investigating if other morphosyntactic categories, e.g. VPs or TPs/CPs, might be presented in the sense suggested above, and if so, how this can be accounted for.

\section{References}

Arregi, Karlos. 2001. Focus and Word Order in Basque. Ms. Massachusetts Intsitute of Technology.

Brandt, Margareta. 1990. Weiterführende Nebensätze. Stockholm: Almqvist \& Wiksell International.

\footnotetext{
${ }^{5}$ The description of a double comment within a V2-RC construction fits nicely with Gärtner's (2001) semantic observation that V2-RCs carry “(proto-) assertional” force.
} 


\section{Stefan Huber}

Brody, Michael. 1995. Hungarian Focus and Bare Checking Theory. Arbeitspapiere des Sonderforschungsbereichs 340 . University of Tübingen.

Chafe, W.L. 1976. Givenness, Contrastiveness, Definiteness, Subjects, Topics, and Point of View. In C. Li, ed., Subject and Topic. New York: Academic Press: 25-55.

den Dikken, M. (2005), A Comment on the Topic of Topic-Comment. Lingua 115: 691-710.

Endriss, Cornelia, and Hans-Martin Gärtner. 2005. Relativische Verbzweitsätze und Definitheit. In: F.-J. d'Avis, ed., Deutsche Syntax: Empirie und Theorie. Göteborg: Acta Universitatis Gothoburgensis:195-220.

Frey, Werner. 2004. The Grammar-Pragmatics Interface and the German Prefield. Sprache \& Pragmatik 52:1-39.

Gärtner, Hans-Martin. 2001. Are there V2 Relative Clauses in German? Journal of Comparative Germanic Linguistics 3(2):97-141.

Gundel, Jeanette, Nancy Hedberg, and Ron Zacharsky. 1993. Cognitive Status and the Form of Referring Expressions in Discourse. Language 69:274-307.

von Heusinger, Klaus. 2002. Specificity and Definiteness in Sentence and Discourse Structure. Journal of Semantics 19:245-274.

Järventaustta, Marja and Valéria Molnár. 2002. Diskurskonfigurationalität im Finnischen und im Ungarischen. Ms. Lund University.

Lambrecht, Knud. 1988. There as a farmer had a dog: Syntactic Amalgams Revisited. Proceedings of the $14^{\text {th }}$ Annual Meeting of the Berkeley Linguistics Society. UC Berkeley, CA:319-339.

Lambrecht, Knud. 1994. Information Structure and Sentence Form. Cambridge: Cambridge University Press.

Meinunger, André. 1998. A Monoclausal Approach to Cleft and Pseudocleft Sentences. ZAS Papers in Linguistics 10:89-105.

Molnár, Valéria. 1993. Zur Pragmatik und Grammatik des TOPIK-Begriffes. In M. Reis, ed., Wortstellung und Informationsstruktur. Tübingen: Niemeyer: 155-202.

Reinhart, Tanya. 1982. Pragmatics and Linguistics: An Analysis of Sentence Topics. Philosophica 27:53-94.

Rizzi, Luigi 1997. The Fine Structure of the Left Periphery. In L. Haegeman, ed., Elements of grammar. Handbook in generative syntax. Dordrecht: Kluwer: 281-337.

Stefan Huber

Department of World Languages

University of South Florida

4202 East Fowler Avenue, CPR 107

Tampa, F1 33620

shuber@cas.usf.edu 